\title{
Experimental Study on Solvent Extraction of Quseir Oil Shale in Egypt
}

\author{
Ehssan Nassef' ${ }^{1}$ Aya Soliman', Ramadan Abou Al-Alla1, Yehia Eltaweel² \\ ${ }^{1}$ Petrochemical Engineering Department, Faculty of Engineering, Pharos University, Alexandria, Egypt \\ ${ }^{2}$ Chemical Engineering Department, Faculty of Engineering, Alexandria University, Alexandria, Egypt \\ Email: ehssan.nassef@pua.edu.eg
}

Received 19 May 2015; accepted 30 June 2015; published 3 July 2015

Copyright (C) 2015 by authors and Scientific Research Publishing Inc.

This work is licensed under the Creative Commons Attribution International License (CC BY).

http://creativecommons.org/licenses/by/4.0/

\section{(c) (i) Open Access}

\begin{abstract}
In the present work, the effect of solvent on the extraction of the organic matter from Quseir's oil shales was studied. The experimental results revealed that the extraction yield obtained by the tetrahydrofuran was very high compared to other solvents. In addition, the solvent had a significant effect on the yield and the composition of the obtained oil. The analysis carried out on the extracted oil showed that the tetrahydrofuran was a very efficient solvent for oil shale extraction, giving a better quality of the oils extracted containing a large proportion of aromatics compounds and fewer amounts of sulphur and paraffin compounds.
\end{abstract}

\section{Keywords}

Oil Shale, Solvent Extraction, Oil

\section{Introduction}

Energy plays an important role in the economic growth and development around the world. Though conventional oil resources like petroleum and natural gas are still the main sources of energy, the depletion of oil reserves and the continuing soaring oil price indicate that countries should turn to unconventional oil resources as reliable and secure energy sources. Oil shale represents one of the largest hydrocarbon resources in the world [1]. Its utilization has received much attention all over the world due to the rise of oil-prices [2]. The petroleum supply/ cost factors create a need for alternative transportation fuels. Shale oil derived fuels are one of these alternatives, and perhaps should be viewed as the most attractive for several reasons: first, shale oil is a superior source of feedstock for transportation fuels-our single largest domestic energy requirement. Utilizing the gas oil conversion flexibility found in most modern refineries, essentially all of the syncrude can be converted to transportation fuels. Jet fuels, diesel and gasoline can all be produced from syncrude, and by choosing the processing con- 
ditions, any product can be maximized. Second, the environmental challenges posed by oil shale development are manageable [3]. Also, oil shale have some potential for the production of several synthetic products such as cement, calcium, alumina, pitches, the carbon adsorbents, zeolites, carbon fibres and other chemicals. These various industrial applications of oil shale have generated in recent years many studies on methods for extracting these oils, such as pyrolysis by conventional heating or under microwave irradiation, extraction with various solvents under sub and supercritical conditions and combustion in fluidized bed reactors [4]. The percentage of organic carbon present can vary from approximately $8 \mathrm{wt} \%$ to $81 \mathrm{wt} \%$. The organic material is normally classified into two components: 1) kerogen, a high-molecular-weight material which is insoluble in normal petroleum solvents; and 2) natural bitumen, a lower-molecular-weight substance which is soluble in benzene and other common petroleum solvents. One distinction between oil shale and coal and tar sands is the amount of ash present. Oil shale normally has an ash yield of $33 \mathrm{wt} \%$ or more, whereas coal and tar sands have significantly smaller amounts [5]. Carbonaceous shales have a wide distribution on the Egyptian surface and in subsurface sedimentary sequences e.g. in sediments of predominantly Carboniferous, Jurassic, Cretaceous, Paleocene and Eocene age. The carbonaceous and black shales in Egypt gained interest since five decades when the phosphorite deposits were discovered and exploited. The phosphorites are intercalated with and capped by black shales that contain considerable amounts of organic matter and are enriched in trace elements, which may be of economic potential. The interest in the black shales all over the world in the last decades principally stem from the widespread recognition that black shales are important source rocks for petroleum or may be used as natural fuel resources. Various previous studies of the carbonaceous shales in Egypt concentrated on an individual location or an individual geological age. Various techniques for the recovery of shale oil are available such as solvent extraction, thermal decomposition (retorting) [6]-[10] and supercritical fluid extraction [4] [11]. Solvent extraction of organic matter is one of the well-known techniques for dissolving organic matter within rock composite. The soluble kerogen decomposition products are removed from the oil shale matrix into a solvent carrier usually present in excess [12]. Some of the advantages of this process are the process selectivity, not very high temperatures needed (under pyrolysis conditions), energetic gain, easily recoverable solvents, possibility of using a big number of solvents, extraction rate of about $90 \%$ of initial kerogen, etc. On the other hand, the most important disadvantage is the lack of thermodynamic equilibrium or solubility data available, mainly in multi component [13]. Shale oil also is produced by the thermal decomposition of its kerogen components. Oil shale must be heated to temperatures between $400^{\circ} \mathrm{C}$ and $500^{\circ} \mathrm{C}$. This heating process is necessary to convert the embedded sediment to kerogen oil and combustible gases. Supercritical fluid extraction is the process of separating one component (the extractant) from another (the matrix) using supercritical fluids as the extracting solvent. Much research has been carried out on a small scale to develop extraction methods which operate at lower temperatures and which remove as much organic material from the shale as possible to maximize the oil yield. These include the use of supercritical, non-hydrogen donor solvents such as water, toluene and methanol. A wide range of hydrogen donor solvents have also been used including tetralin and hydrogenated recycle distillate [14]. Supercritical water extraction is receiving particular interest in oil shale processing due to the oil yield increase, ease of removal of the products, its compatiblity with the environment and its already accepted role as a means for shale oil processing for production of special chemicals like ethylene, propylene, benzene, toluene, and xylene [15]. The present study aimed to investigate the effect of different solvents on the extraction of shale oil from Egyptian oil shale obtained from Al-Quseir area for obtaining maximum yield of oil. Also it is aimed to study the effect of operating parameters including particle size, extraction time, stirring speed and solvent to oil shale ratio on rate of extraction.

\section{Material and Methods}

\subsection{Solvent Extraction Method}

The oil shale used in this work was obtained from Al-Quseir area deposit located in the South of Hurghada. This deposit consists of several layers that are in turn subdivided in sub-layers, each having a different amount of organic matter. The oil shale samples used were crushed and sieved The powdered shale (100 g, grain size 0.063 $0.08 \mathrm{~mm}$ ) as shown in Figure 1. A $200 \mathrm{gm}$ of the solvent were introduced in the three neck round flask as shown in Figure 2. The mixture was then subjected to mechanical stirrer for $4 \mathrm{~h}$. Extraction was carried at the boiling points of each solvent. The shale was then measured and from the difference between the weight of the spent shale, the original weight of the sample and the amount of oil extracted the weight of the adsorbed solvent can be determined. 


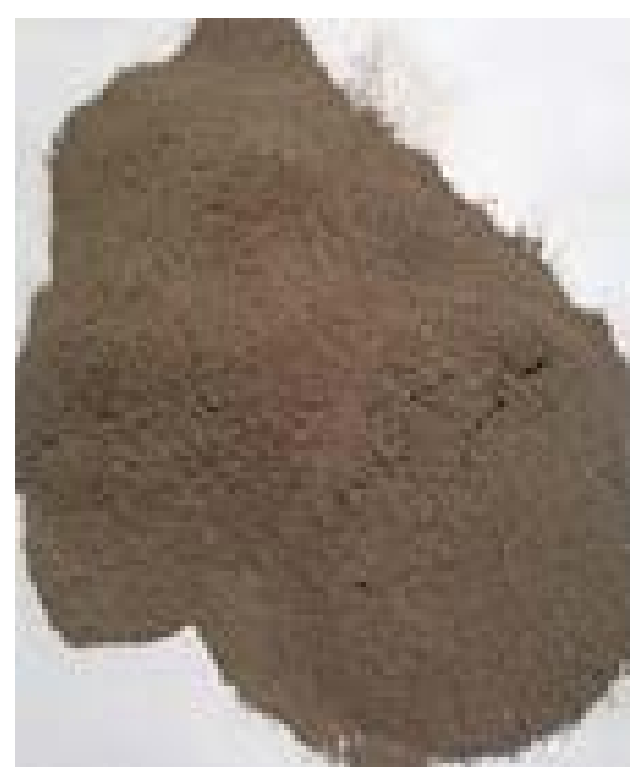

Figure 1. Fully-crushed oil shale.

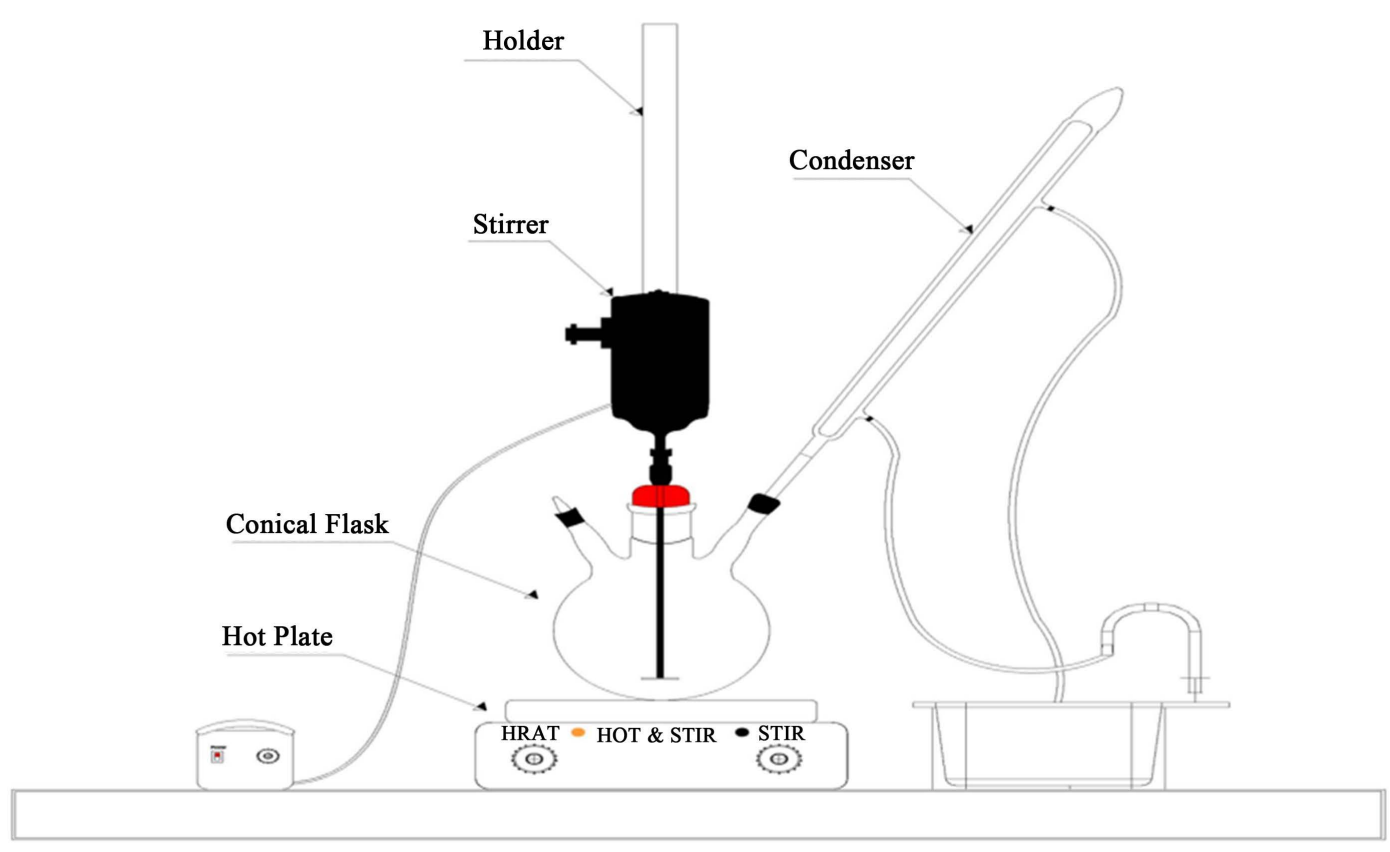

Figure 2. Experimental set-up of the recovery process of oil by solvent extraction.

\subsection{Analysis of Oil Shale}

The elemental analysis of oil shale was performed at National Research Institute in Cairo; Egypt the data is given in Table 1.

\section{Results and Discussion}

\subsection{Solvent Selection and Yield Calculation}

The rate of extraction of bitumen depends on the type of organic solvent used. If the force of attraction between the bitumen and the solvent is greater than that between the solvent molecules or of the dissolution of the bitumen, then the bitumen can be easily extracted. Different organic solvents pure and combined were used for 
Table 1. The elemental analysis of oil shale sample.

\begin{tabular}{|ccccc}
\hline Oil Shale Sample & $\mathrm{C}$ & $\mathrm{N}$ & $\mathrm{S}$ & $\mathrm{H}$ \\
\hline & $4.69 \%$ & $0.06 \%$ & $0.2 \%$ & $1.5 \%$ \\
\hline
\end{tabular}

extraction [16] [17]. The oil yield was computed for 50 gm shale and 100 gm solvent. Comparison among these solvents and selectivity of the best solvents was made qualitatively based on quantity and quality of yield and of solvent recovered. As shown in Figure 3 the yield obtained by the action of THF is much higher than those obtained during the extraction of organic matter from the same sample using other solvents and this results in accordance with [18]-[20]. The extraction of an analyte from sample consists of several steps, including solvation of the analyte by extraction solvent, desorption from the matrix surface and finally, transportation of the analyte into the bulk extraction liquid. The solvent can play different roles in the extraction process, either solubilization and extraction of smaller, unbound molecules, which are present in oil shale matrix, and/or by attacking the kerogen structure. Solvents having different physical and chemical properties can break bonds based on electron donor-electron acceptor interactions and hydrogen bonding. Water, alcohols, or aliphatic amines could be such solvents to improve the conversion of kerogen matrix into smaller molecules. By comparing this results with Estonian oil shale it was found that for the same solvents [THF, Toluene, n-hexane] the Egyptian oil shale has higher percentage yield of oil produced.

\subsection{Effect of Solvent to Oil Shale Ratio}

The quantity of solvent used for extraction should be large enough to impregnate all the oil shale particles with the solvent and high enough to allow the contact of the solvent with all possible accessible soluble hydrocarbons in the oil shale. Results showed that the yield increased with increasing the solvent to oil shale ratio until it reached 2:1 and after that the increase in the yield is negligible as shown in Figure 4.

\subsection{Effect of Extraction Time}

The effect of extraction time on the yield is shown in Figure 5. It shows that as the time of extraction increases the yield increases too up to a time of four hours. Beyond this time, the effect of time became not very significant. These results in accordance with reference [19] [20] by longer time reactions confirm the ease of conversion of the shale to oil.

\subsection{Effect of Particle Size}

Particle size is an important parameter in extraction of oil shale. It is a direct function of the total surface area available for extraction. The smaller the size of the particles the greater is the interfacial area between the solid and the liquid and therefore the rate of transfer of material. Effect of the particle size on extraction is shown in Figure 6. It was found that the yield decreases with increasing particle size from $1.0 \mathrm{~mm}$ to $4.0 \mathrm{~mm}$. It was found that $1.0 \mathrm{~mm}$ as the optimum particle size that provided the sufficient mass transfer without agglomeration of particles which in turn, ensured the free mass transfer mechanism. It was also noticed that the larger the particle size the smaller the amount of solvent adsorbed and the lower the extraction rate, so the optimum particle size was taken as $1.0 \mathrm{~mm}$. These results are in agreement with the results obtained by Haddadin and Pinwen [21] [22].

\subsection{Physicochemical Properties of the Extracts}

Shale oil was analyzed by gas chromatography (GC) as shown in Figure 7 with the intent of establishing a preliminary set of guidelines and conditions. It was observed that the sample contains high hydrocarbon range from C12 - C18 in high percentage. The analysis of Quseir shale oil was performed using a $60 \mathrm{~m}$ DB-1 fused silica capillary column. The column internal diameter was $0.32 \mu \mathrm{MM}$ and the film thickness was $0.5 \mu \mathrm{MM}$. The column was programmed $40^{\circ} \mathrm{C}$ at $5{ }^{\circ} \mathrm{C} / \mathrm{min}$. Helium was used as a carrier gas at a pressure $1.4 \mathrm{~kg} / \mathrm{cm}^{2}$. These results in accordance with [23]. 


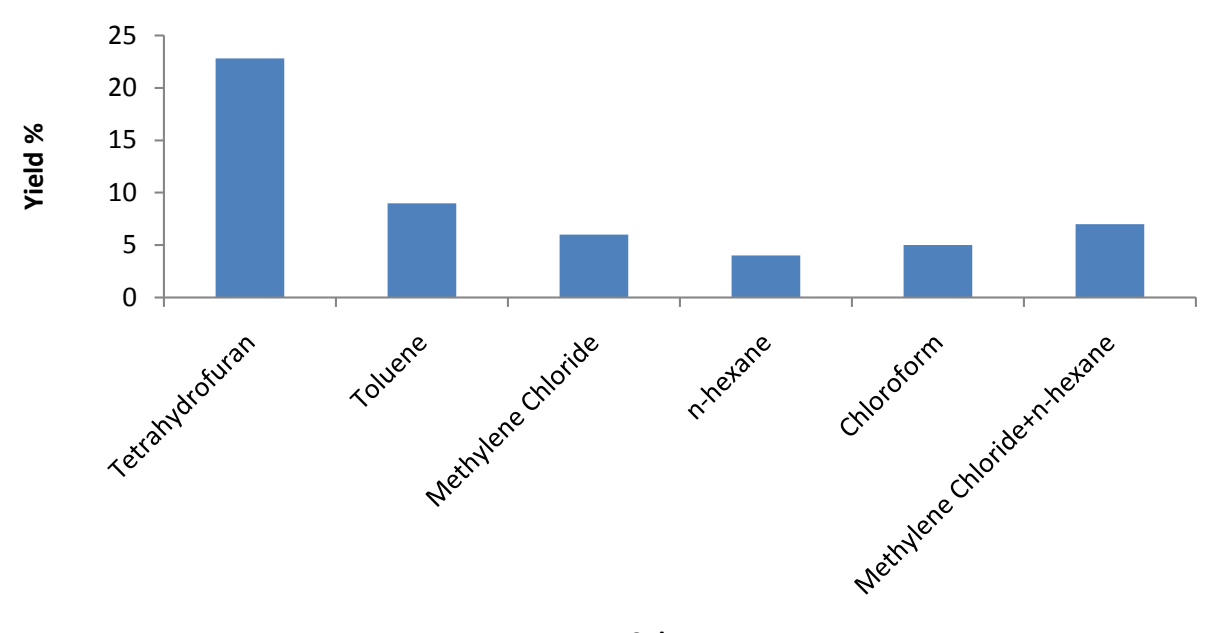

Solvents

Figure 3. Comparison of the yield percentage (Yield \%) for different solvents.

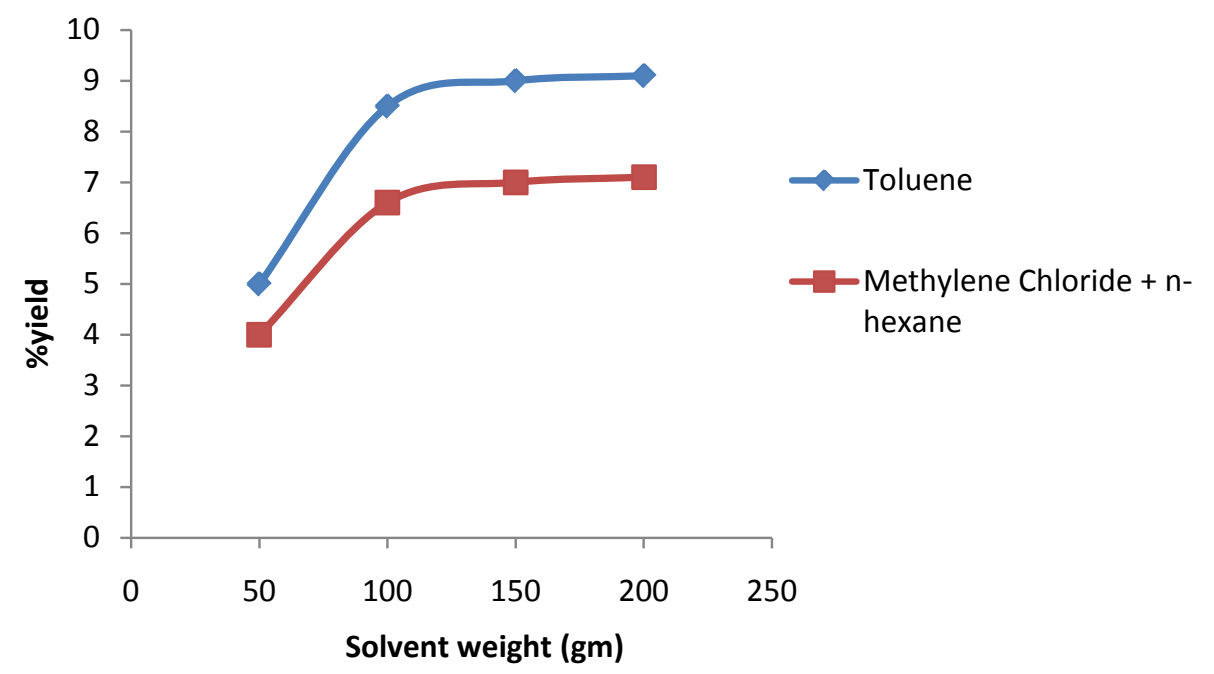

Figure 4. Effect of solvent to oil shale ratio.

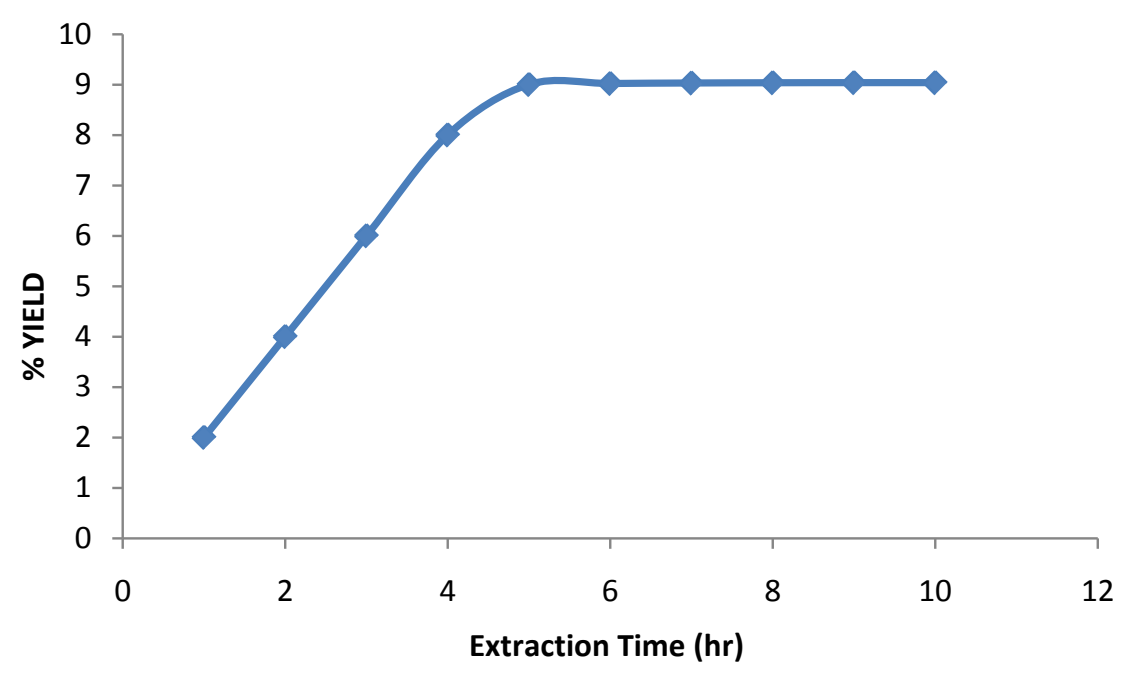

Figure 5. The effect of extraction time on the yield percentage (Yield \%). 


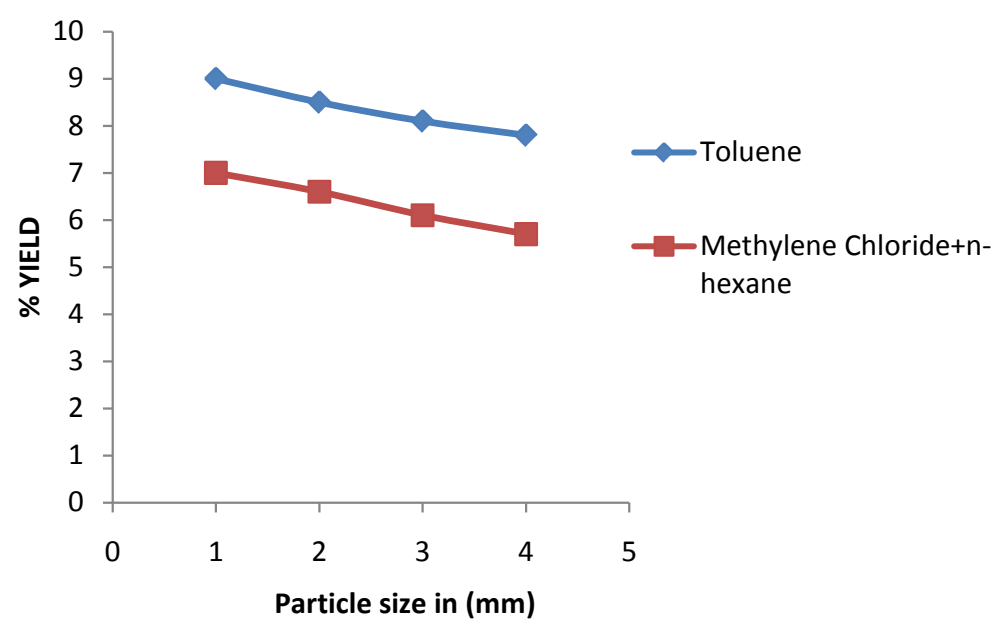

Figure 6. Effect of particle size on the percentage yield.

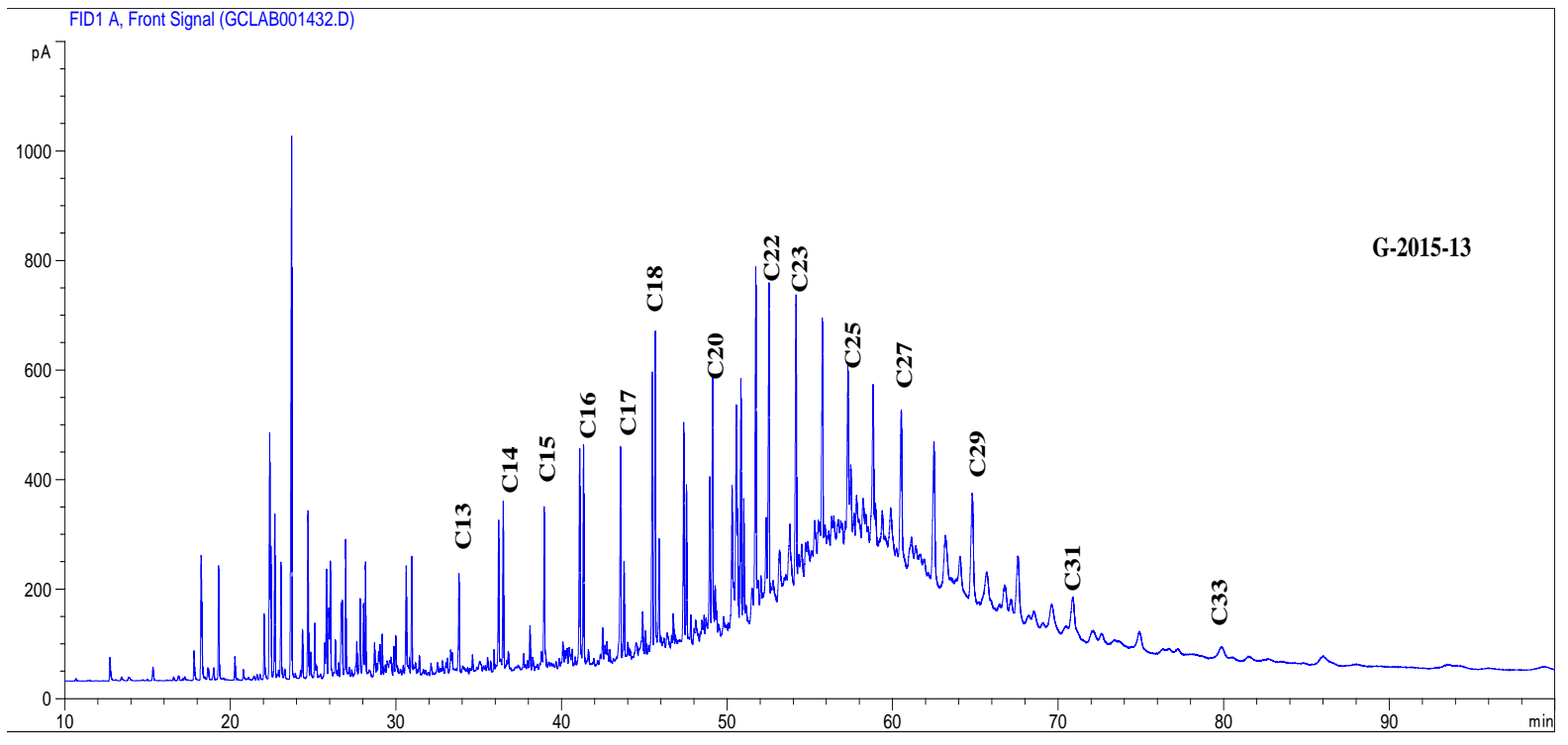

Figure 7. GC of oil shale extracts.

\section{Conclusion}

Demand for light hydrocarbons has been steadily increasing in the market with a corresponding decrease in heavy hydrocarbon demand. Therefore, there is a need to develop environmentally friendly and efficient technologies for conversion of heavy molecular weight hydrocarbons. In the present study, the nature of solvent was found to have a very significant effect on the yield of recovery and the composition of the oils obtained. The oil yield obtained by THF extraction is significantly higher than those obtained by other solvents.

\section{References}

[1] Baldwin, R.M. and Chen, K.W. (1987) Pyrolysis and Hydropyrolysis of Two Carbonaceous Australian Oil Shales in Supercritical Toluene and Tetralin. Fuel, 66, 353-357. http://dx.doi.org/10.1016/0016-2361(87)90093-7

[2] Al-Makhadmeh, L., Maier, J., Al-Harahsheh, M. and Scheffknecht, G. (2013) Oxy-Fuel Technology: An Experimental Investigations into Oil Shale Combustion under Oxy-Fuel Conditions. Fuel, 103, 421-429. http://dx.doi.org/10.1016/j.fuel.2012.05.054

[3] Duir, J.H., Randle, A.C. and Reeg, C.P. (1990) Unocal's Parachute Creek Oil Shale Project. Fuel Processing Technology, 25, 101-117. http://dx.doi.org/10.1016/0378-3820(90)90099-E 
[4] Abourriche, A.K., Oumam, M., Hannache, H., Birot, M., Abouliatim, Y., Benhammou, A., El Hafiane, Y., Abourriche, A.M., Pailler, R. and Naslain, R. (2013) Comparative Studies on the Yield and Quality of Oils Extracted from Moroccan Oil Shale. Journal of Supercritical Fluids, 84, 98-104. http://dx.doi.org/10.1016/j.supflu.2013.09.018

[5] Noble, R.D., Tucker, W.F. and Harris, H.G. (1982) Isothermal Oil Shale Pyrolysis: Oil Generation and Composition at Various Pressures. Fuel, 61, 482-484. http://dx.doi.org/10.1016/0016-2361(82)90079-5

[6] Temraz, M. (2005) Mineralogical and Geochemical Studies of Carbonaceous Shale Deposits from Egypt. Ph.D. Thesis, Technischen Universität Berlin, Fakultät VI Bauingenieurwesen und Angewandte Geowissenschaften.

[7] Deng, S., Wang, Z., Gu, Q., Meng, F., Li, J. and Wang, H. (2011) Extracting Hydrocarbons from Huadian Oil Shale by Sub-Critical Water. Fuel Processing Technology, 92, 1062-1067. http://dx.doi.org/10.1016/j.fuproc.2011.01.001

[8] Torrente, M.C. and Galan, M.A. (2011) Extraction of Kerogen from Oil Shale (Puertollano, Spain) with Supercritical Toluene and Methanol Mixtures. Industrial and Engineering Chemistry Research, 50, 1730-1738. http://dx.doi.org/10.1021/ie1004509

[9] Wolson, A., Elmugrabi, Y., Levi, R., Tavor, D. and Winsiak, J. (2011) Green Process for Simultaneous Extraction of Oil Shale and Enrichment of Ethanol. Oil Shale, 28, 516-527. http://dx.doi.org/10.3176/oil.2011.4.05

[10] Niu, M., Wang, S., Han, X. and Jiang, X. (2013) Yield and Characteristics of Shale Oil from the Retorting of Oil Shale and Fine Oil-Shale Ash Mixtures. Applied Energy, 111, 234-239. http://dx.doi.org/10.1016/j.apenergy.2013.04.089

[11] Canıaz, R.O. and Erkey, C. (2014) Process Intensification for Heavy Oil Upgrading Using Supercritical Water. Chemical Engineering Research and Design, 92, 1845-1863.

[12] Na, J.G., Im, C.H., Chung, S.H. and Lee, K.B. (2012) Effect of Oil Shale Retorting Temperature on Shale Oil Yield and Properties. Fuel, 95, 131-135.

[13] G-Hourcade, M.L., Torrente, C. and Galán, M.Á. (2007) Study of the Solubility of Kerogen from Oil Shales in Puertollano, Spain, in Supercritical Toluene and Methanol. Fuel, 86, 698-705. http://dx.doi.org/10.1016/j.fuel.2006.07.013

[14] Fei, Y., Marshall, M., Jackson, W.R., Gorbaty, M.L., Amer, M.W., Cassidy, P.J. and Chaffee, A.L. (2012) Evaluation of Several Methods of Extraction of Oil from a Jordanian Oil Shale. Fuel, 92, 281-287 http://dx.doi.org/10.1016/j.fuel.2011.08.019

[15] Haddadin, R.A. (1974) Tetralin Extraction of Jordan Oil Shale with Ultrasonic Irradiation. Fuel, 53, 182-185. http://dx.doi.org/10.1016/0016-2361(74)90008-8

[16] Ekinci, E. and Yürüm, Y. (1995) Steam and Coprocessing of Oil Shales. In: Snape, C.E., Ed., Composition, Geochemistry and Conversion of Oil Shales, Kluwer Academic Publishers, Dordrecht, 247-262. http://dx.doi.org/10.1007/978-94-011-0317-6_15

[17] Anabtawi, M.Z. and Uysal, B.Z. (2002) Combustion Technology for a Clean Environment, Technology \& Engineering.

[18] Koel, M., Ljovin, S., Hollis, K. and Rubin, J. (2001) Using Neoteric Solvents in Oil Shale Studies. Pure and Applied Chemistry, 73, 153-159. http://dx.doi.org/10.1351/pac200173010153

[19] Fei, Y., Marshall, M., Roy Jackson, W., Gorbaty, M.L., Amer, M.W., Cassidy, P.J. and Chaffee, A.L. (2012) Evaluation of Several Methods of Extraction of Oil from a Jordanian Oil Shale. Fuel, 92, 281-287. http://dx.doi.org/10.1016/j.fuel.2011.08.019

[20] Matouq, M., Koda, S., Maricela, T., Omar, A. and Tagawa, T. (2009) Solvent Extraction of Bitumen from Jordan Oil Shale Assisted by Low Frequency Ultrasound. Journal of the Japan Petroleum Institute, 52, 265-269. http://dx.doi.org/10.1627/jpi.52.265

[21] Haddadin, R.A. (1980) Kinetics of Tetralin Extraction of Jordan Oil Shale. Fuel, 59, 535-538. http://dx.doi.org/10.1016/0016-2361(80)90186-6

[22] Zhao, P.W., Zhao, Y.J., Zou, C.J. and Gu, T. (2013) Study on Ultrasonic Extraction of Kerogen from Huadian Oil Shale by Solvents. Oil Shale Journal, 30, 491-500.

[23] Al-Alla, R.A. and Nassef, E. (2015) Extraction of Oil from Egyptian Oil Shale. Journal of Petroleum \& Environmental Biotechnology, 6, 205. 